\title{
DESMISTIFICANDO A INTRADUZIBILIDADE DA TERMINOLOGIA JURÍDICA
}

\author{
DEMYSTIFYING THE UNTRANSLATABILITY OF LEGAL TERMINOLOGY
}

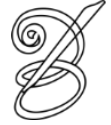 \\ Janine Pimentel ${ }^{\mathrm{i}}$ \\ (PhD Tradução - OLST ${ }^{\mathrm{ii}} /$ CLUNL ${ }^{\mathrm{iii}}$ ) \\ janine.m.pimentel@gmail.com
}

\begin{abstract}
Resumo: A criação de recursos terminológicos multilingues, em geral, e de recursos terminológicos multilingues cobrindo a área do direito, em particular, depara-se frequentemente com o problema de ligar terminologias potencialmente anisomórficas devido a diferenças entre sistemas conceptuais, linguísticos e culturais. Esta dificuldade tem feito com que a qualidade e até mesmo a possibilidade da tradução de textos jurídicos tenha sido questionada, pois para alguns autores certos termos jurídicos são simplesmente intraduzíveis. Nesta contribuição pretende-se mostrar que a intraduzibilidade da terminologia jurídica pode ser relativizada. Para tal propõe-se uma metodologia baseada na teoria da semântica das frames (Fillmore 1977, 1982, 1985; Fillmore and Atkins 1992) para a identificação de equivalentes de termos jurídicos, nomeadamente de verbos jurídicos. Esta metodologia foi testada na compilação do JuriDico (http://olst.ling.umontreal.ca/juridico), um recurso lexical bilíngue (inglês-português) que pretende descrever a terminologia usada nos acórdãos do Supreme Court of Canada e do Supremo Tribunal de Justiça de Portugal. O objectivo principal deste dicionário, ainda em fase inicial, é a de oferecer aos tradutores os vários tipos de equivalentes terminológicos para que eles possam produzir traduções de qualidade.
\end{abstract}

Palavras-chave: equivalência, terminologia jurídica, tradução, dicionário

\begin{abstract}
The compilation of multilingual terminological resources, in general, and of multilingual resources covering the subject field of the law, in particular, often raises the problem of linking potentially anisomorphic terminologies due to differences in conceptual, linguistic and cultural systems. This challenge has contributed to the debate on the translatability of legal terminology because some authors believe that certain terms are simply untranslatable. This contribution attempts to demonstrate that the untranslatability of legal terminology should not be over-generalized and proposes a methodology based on the theory of Frame Semantics (Fillmore 1977, 1982, 1985; Fillmore and Atkins 1992) to identify the equivalents of legal terms, namely the equivalents of specialized verbs. This methodology has been tested throughout the compilation of JuriDiCo (http://olst.ling.umontreal.ca/juridico), a bilingual lexical resource (English-Portuguese) that describes the terminology used in the judgments issued by the Supreme Court of Canada and by the Supremo Tribunal de Justiça de Portugal. The main objective of this dictionary, which is an ongoing project, is to provide translators with suited equivalents so that they are able to produce high quality translations.
\end{abstract}

Keywords: equivalence, legal terminology, translation, dictionary

\section{Introdução}

No seu dicionário técnico bilingue, WÜSTER (1969), o fundador da Terminologia, mostra que um termo inglês e um termo francês são equivalentes quando estão associados a 
um mesmo conceito. Uma vez que o objectivo principal de WÜSTER é o de identificar o sistema conceptual de uma dada área de especialidade, o comportamento linguístico dos termos é negligenciado e os equivalentes parciais não são identificados como tal. No caso da criação recursos terminológicos multilingues na área do direito, esta abordagem é claramente insuficiente. Em primeiro lugar, tem sido mostrado que muitos dicionários jurídicos ainda não indicam que certos equivalentes são parciais nem em que situações o são, o que os torna inviáveis para a tradução (DE GROOT e VAN LAER, 2008). Em segundo lugar, tem-se sublinhado que a equivalência terminológica estabelece-se sempre não só num plano sistémico (langue), mas também num plano textual (parole) porque o comportamento sintagmático dos termos desempenha um papel importante na escolha do equivalente terminológico correcto (ROGERS, 2008; PIMENTEL, 2012). Para, além disso, desde há muito tempo que a qualidade e até mesmo a possibilidade da tradução de textos jurídicos tem vindo a ser questionada, pois, para alguns autores, certos termos jurídicos são simplesmente intraduzíveis devido à ausência de um conceito equivalente noutra cultura. É provavelmente por estas razões que os dicionários jurídicos actualmente existentes, sobretudo os que cobrem

56 os pares de línguas como o Português-Inglês, nem sempre são úteis para os tradutores de textos jurídicos.

Neste sentido, um dos principais objectivos da compilação do JuriDico (http://olst.ling.umontreal.ca/juridico), um recurso lexical bilíngue (inglês-português) que pretende descrever a terminologia usada nas decisões de tribunais de alta instância, é a de oferecer aos tradutores os vários tipos de equivalentes terminológicos seleccionados por meio de uma metodologia rigorosa e detalhada que se baseia na informação linguística e extralinguística associada a cada um dos termos. Por informação linguística entenda-se as estruturas sintáctico-semânticas dos termos bem como as suas colocações, e por informação extralinguística entenda-se os cenários conceptuais evocados pelos termos. Este trabalho baseia-se na teoria da semântica das frames (FILLMORE, 1976, 1977, 1982, 1985, FILLMORE e ATKINS, 1992), no projecto FrameNet (RUPPENHOFER et al, 2010), bem como na metodologia desenvolvida no Observatoire de linguistique Sens-Texte da Universidade de Montreal para compilar o DiCoInfo e o DiCoEnviro (L'HOMME, 2008).

Esta contribuição está organizada da seguinte forma. Primeiro, começamos por rever os pressupostos do debate sobre a intraduzibilidade da tradução e da terminologia jurídica (secção 2). Na Secção 3, apresentamos os princípios teóricos e metodológicos nos quais a compilação de JuriDico foi baseada, e resumimos a metodologia utilizada para compilar este 
dicionário, nomeadamente a metodologia utilizada para identificar os vários tipos de equivalentes. A Secção 4 ilustra os resultados obtidos e aplica-os à tradução para o Português de frases tiradas de um corpus de decisões canadianas escritas em inglês. Finalmente, discutimos os resultados e tiramos algumas conclusões relativamente à traduzibilidade da terminologia jurídica.

\section{Da (in)traduzibilidade da terminologia jurídica}

A questão da intraduzibilidade do direito está relacionada com uma questão mais geral que tem sido debatida filosoficamente ao longo dos séculos: será que a tradução é teoricamente possível? Esta questão tem sido tradicionalmente abordada a partir de dois pontos de vista radicalmente diferentes: a perspectiva universalista e a perspectiva monadista ou relativista. De acordo com DE PEDRO (1999, p. 550), os defensores do primeiro ponto de vista (por exemplo, CHOMSKY) afirmam que a existência de universais linguísticos garante a traduzibilidade, enquanto aqueles que endossam o segundo ponto de vista (por exemplo, LEIBNIZ, HUMBOLDT, SCHLEGEL e SCHLEIERMACHER) afirmam que cada comunidade linguística interpreta a realidade da sua própria maneira e que isso coloca em risco a traduzibilidade.

Tal como o debate sobre a (in)traduzibilidade, em geral, no direito comparado, também, esta questão tem sido abordada a partir de dois pontos de vista opostos. Poirier explica que: "Appliquée au droit, cette notion signifie que les concepts de deux systèmes juridiques différents ne peuvent être comparés entre eux parce qu'ils appartiennent à des cultures différentes et que pour cette raison ils ne peuvent pas être traduits d'une culture à l'autre" (POIRIER, 2005, p. 553). Numa extremidade do pólo, estão os autores que afirmam que o direito é incomensurável, tais como DAVID (1974) e SACCO (1991). Em geral, o principal argumento apresentado é que o direito não pode ser traduzido porque é consubstancial à língua e, portanto, um dos domínios mais impregnados culturalmente. Por conseguinte, os conceitos jurídicos inexistentes no sistema de destino são intraduzíveis. As críticas feitas a este ponto de vista sustentam que apesar dos termos law, direito e droit se referirem a tradições distintas, consoante o leitor ser inglês, português ou francês, todos os três termos podem ser traduzidos. Portanto, na outra extremidade do pólo, muitos especialistas consideram que a tradução jurídica é viável e altamente produtiva, porque é uma necessidade socio-cultural (MOUNIN, 1965; HARVEY, 2002). Os defensores desta posição também argumentam que, apesar da tradução jurídica não ser uma tarefa fácil, pode ocorrer 
por meio de um continuum de equivalência (CAO, 2007). Contrariamente à abordagem universalista que afirma que as línguas têm sempre elementos universais, a intraduzibilidade é vista aqui como um conceito abstracto que serve para destacar o grau de complexidade da tradução jurídica.

O debate sobre a traduzibilidade do direito é relevante para a tradução jurídica, bem como para a Terminologia, pois a anisomorfia dos sistemas conceptuais devido a mundivisões diferentes levanta um desafio na hora de seleccionar os equivalentes dos termos jurídicos. Um exemplo disso é a polémica em torno da tradução do termo português arguido, para o qual foi criado uma entrada na Wikipedia por causa do caso Maddie. A história de Madeleine McCann de três anos de idade, que desapareceu em Maio de 2007 durante as férias com seus pais e irmãos gémeos no sul de Portugal, ficou conhecida em todo o mundo devido à sua enorme cobertura nos meios de comunicação social. A investigação sobre o desaparecimento desta menina envolveu a cooperação da polícia britânica e portuguesa e demonstrou as diferentes metodologias empregadas por cada uma, no que diz respeito a aspectos como a quantidade de informação divulgada ao público e o estatuto legal das pessoas envolvidas no processo. À 58 medida que a investigação da polícia avançou, os pais de Maddie, Kate e Gerry McCann, receberam o estatuto de arguido. O povo britânico que seguia o drama dos seus compatriotas desconhecia o conceito de arguido. Efectivamente, o Direito Penal Português faz uma distinção entre arguido e suspeito. Um arguido é alguém que está sendo tratado pela polícia como mais do que uma testemunha e mais do que um suspeito:

[...] arguido é todo aquele em relação ao qual há indícios suficientemente seguros de que cometeu um ilícito criminal. Trata-se, pois, de uma qualidade reportada a uma situação já de alguma consistência face a um determinado crime e que está para além da de simples suspeito [...]. Desta singela caracterização poderemos desde logo alcançar que a posição processual do suspeito perante o ilícito criminal é mais frágil, mais ténue, do que a do arguido, uma vez que em relação a ela ou ainda não há crime ou, havendo-o, os indícios da sua implicação nele são ainda muito imprecisos. (SANTOS et al., 2010, p. 107).

Os mesmos autores e ANTUNES (2004) explicam que um arguido pode adquirir este estatuto por vontade própria ou pode ver ser-lho atribuído pela polícia. Ao contrário, um suspeito é alguém que é considerado como tendo cometido ou participado num crime ou que está prestes a cometer ou participar num crime e não pode entrar neste estado voluntariamente. Todavia, o Direito Penal Britânico não faz a mesma distinção devido ao facto do seu sistema penal ser diferente. Por esse motivo, a análise da imprensa britânica 
naquele momento revela que os jornalistas que escreviam sobre o caso tinham duas opções: ou definiam o conceito porque, em inglês, o termo arguido não tem um equivalente perfeito; ou utilizavam os equivalentes parciais, formal suspect and suspect. A ausência de uma explicação sobre o conceito ou da menção que os equivalentes eram apenas parciais era inevitavelmente geradora de controvérsia.

Nas próximas secções apresenta-se uma metodologia para identificar os equivalentes de termos jurídicos e avaliar o seu grau de equivalência.

\section{Elaboração de um dicionário jurídico bilingue}

\subsection{Apresentação do dicionário}

O JuriDico é um dicionário bilíngue (inglês-português) que pretende descrever a terminologia usada nos acórdãos dos tribunais de alta instância e oferecer aos tradutores os vários tipos de equivalentes terminológicos (Figura 1).

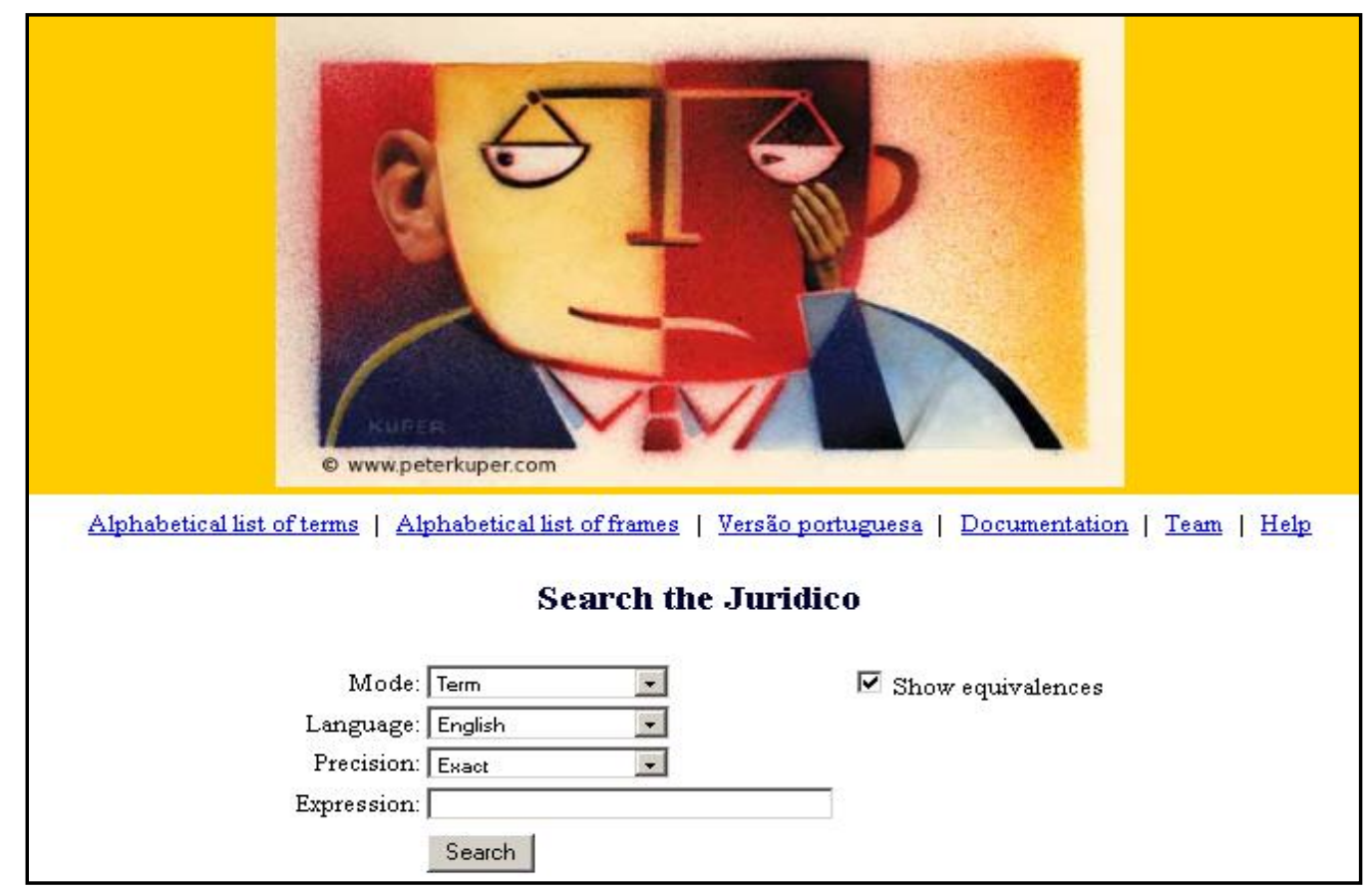

Figure 1. Página inicial do JuriDico.

Este trabalho baseia-se na teoria da semântica das frames (FILLMORE, 1976, 1977, 1982, 1985, FILLMORE e ATKINS, 1992), no projecto FrameNet (RUPPENHOFER et al, 2010.), bem como na metodologia desenvolvida no Observatoire de linguistique Sens-Texte da Universidade de Montreal para compilar o DiCoInfo e o DiCoEnviro (L'HOMME, 2008). Uma frame ou cenário conceptual é uma situação que se apresenta estruturada por uma 
constelação de participantes que a distinguem de outras situações. O leitor pode ler uma descrição detalhada dos princípios teóricos e da sua aplicação à elaboração deste dicionário em PIMENTEL (2012).

Actualmente, o JuriDico pode ser consultado de três maneiras: os utilizadores podem percorrer uma lista inglesa e uma lista portuguesa de termos ordenadas alfabeticamente; podem usar um motor de busca; ou percorrer uma lista de frames ordenada alfabeticamente (Figura 1).

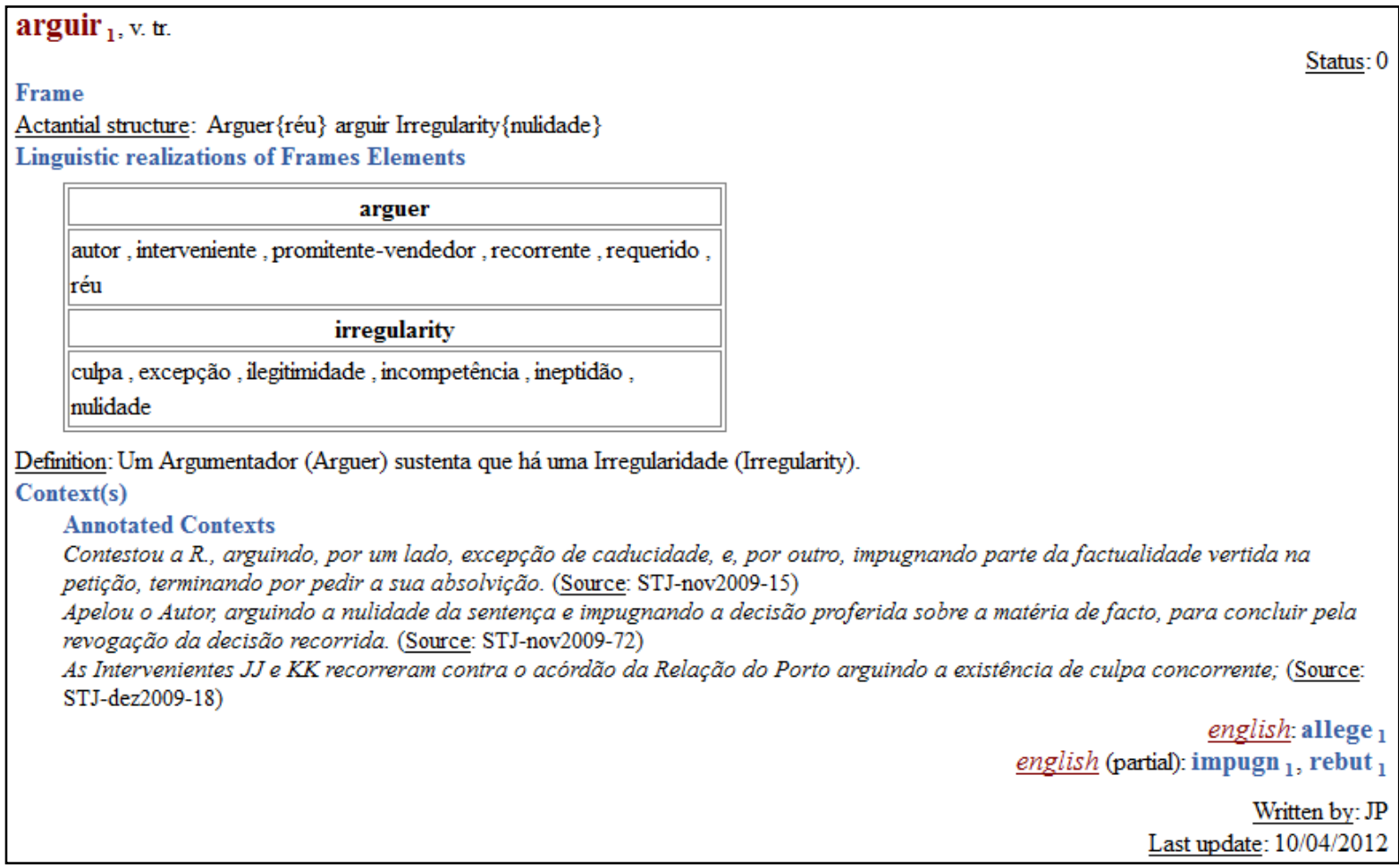

Figure 2. Exemplo de uma ficha terminológica.

Por enquanto os termos descritos no dicionário são todos verbos especializados, mas, no futuro, pretende-se incluir termos pertencentes a outras categorias gramaticais. Cada ficha terminológica do JuriDico contém os seguintes campos (Figura 2):

- Entrada. Neste campo menciona-se o termo com o seu número de acepção, por exemplo, arguir. . Um número é sempre apresentado, mesmo que o termo tenha apenas uma acepção. O número da acepção é utilizado em todas as outras secções nas quais o termo aparece. Cada entrada tem uma etiqueta indicando a categoria gramatical do termo. Os verbos são marcados como sendo transitivos, intransitivos ou pronominais. 
- Frame. Ao clicar no campo chamado frame, os utilizadores terão acesso a quatro campos: o nome da frame, a definição da frame, os participantes da frame e outros termos que evocam o mesmo cenário. Por exemplo, [Contesting] é o nome atribuído à frame que o verbo arguir evoca e é definida da seguinte maneira: "This frame is related to the Argumentation frame. Whereas in the Argumentation frame the Arguer presents a statement, a reason or fact for or against the matter under discussion, in this frame the Arguer questions the validity of a statement or of a fact. This frame has three core FEs, i.e. Arguer, Irregularity and Evidence. Not all terms that evoke this frame profile the FE Evidence". Os nomes das frames e dos seus participantes começam por uma letra maiúscula e são sempre fornecidos em inglês. Os participantes nas frames encontram-se divididos em participantes obrigatórios (core Frame Elements ou core FEs) e participantes opcionais (non-core Frame Elements ou non-core FEs). Uma breve definição é fornecida para cada participante obrigatório. A secção "Other terms" lista os termos na mesma língua que foram agrupados na mesma frame e que podem ser sinónimos, quase-sinónimos e antónimos

- Estrutura actancial. A estrutura actancial, também chamada estrutura argumental, indica o número de actantes do termo e os seus papéis semânticos. Este campo existe no DiCoInfo mas não existe na FrameNet. Foi adoptado aqui com o objectivo de mostrar a forma como os termos evocam um determinado cenário. Enquanto os core FEs são de natureza conceptual, os actantes são entidades linguísticas. Por conseguinte, os actantes dos termos podem ou não corresponder aos core FEs da frame que eles evocam, porque os termos podem evocar a frame de maneiras diferentes. Por exemplo, a estrutura actancial do termo arguir 1 contém dois core FEs da frame [Contesting], no caso Arguer e Irregularity, mas esta contém três: Arguer, Irregularity e Evidence.

- Realizações linguísticas dos FEs. Ao clicar neste campo, os utilizadores têm acesso aos termos que correspondem às realizações dos actantes do verbo e que são, na sua maioria, o núcleo de sintagmas nominais.

- Definição. Este campo fornece uma definição do verbo que pode ou não corresponder exactamente à definição da frame. Por exemplo, a definição de arguir $_{1}$ ilustra a forma como este verbo oferece uma perspectiva sobre a frame [Contesting] (Figura 2). 
- Contextos. Este campo inclui dois tipos de informação: três contextos ilustrativos do termo, e cerca de vinte contextos anotados juntamente com um quadro-síntese que contém as propriedades sintáctico-semânticas do termo. Os utilizadores podem aceder aos contextos anotados, bem como à tabela com as propriedades sintáctico-semânticas do termo clicando em "Contextos anotados".

- Equivalentes. Aqui, indica-se os equivalentes totais e parciais dos termos. Quando os equivalentes são apenas parciais, a menção "partial” é acrescentada.

\subsection{Metodologia de compilação}

Nesta secção, resume-se a metodologia adoptada na compilação do JuriDico por meio do exemplo do verbo arguir. Todos os verbos e os dados que suportam as descrições supramencionadas foram extraídos de um corpus comparável de decisões autênticas produzidas pela Supreme Court of Canada e pelo Supremo Tribunal de Justiça de Portugal. Este corpus totaliza aproximadamente dois milhões e meio de palavras para cada língua e é composto por um único género de textos.

Por meio de um extractor de termos chamado Termostat (DROUIN, 2003), que calcula a especificidade das palavras que ocorrem num corpus especializado comparando-as com a sua frequência nesse corpus e num corpus de língua geral, extraímos uma lista de candidatos a termos para o português e para o inglês. Como queríamos começar por estudar os verbos especializados, seleccionámos apenas os candidatos a termo pertencentes a esta categoria gramatical. Por exemplo, o verbo arguir é um dos verbos extraídos pelo Termostat que tinha um coeficiente de especificidade muito elevado. Usando um programa de concordâncias examinámos o comportamento do verbo no corpus, de modo a verificar se arguir tinha um significado especializado. Para tal aplicámos um conjunto de critérios léxico-semânticos que têm sido usados para validar o estatuto especializado dos candidatos a termos (L'HOMME, 2004). Assim, observámos que arguir era um termo válido pelas seguintes razões:

- O verbo arguir parece ter um significado relacionado com os procedimentos seguidos nos julgamentos;

- Os seus actantes são termos (recorrente, requerido, réu, culpa, ilegitimidade, incompetência, ineptidão, nulidade);

- Os seus derivados morfológicos são termos (arguido); 
- O verbo estabelece relações paradigmáticas com outros termos da área de especialidade (contestar, alegar, impugnar).

Arguir parecia evocar um cenário em que alguém apresenta uma declaração, uma razão ou facto a favor ou contra a matéria em discussão, questionando assim a validade de uma declaração ou um facto. Trata-se de um verbo transitivo com dois actantes (Arguer e Irregularity). $\mathrm{O}$ actante chamado Arguer refere-se a entidades humanas que, nos julgamentos, desempenham o papel específico de denunciar uma irregularidade por meio de argumentação sustentada por provas. No que diz respeito ao segundo actante, PRATA (2005, p. 580) explica que: “A irregularidade de um acto ou negócio jurídico provém, tal como a invalidade, de um vício interno do acto, que, sendo, no entanto, menos grave, não acarreta a sua destruição, apenas dando lugar a sanções pela sua prática".

Depois de validar o estatuto especializado do verbo arguir, seleccionámos cerca de vinte contextos que ilustram o termo, anotámos os participantes obrigatórios e opcionais no significado do termo, e guardámos toda a informação num banco de dados em formato xml. Procedemos desta forma até completarmos a descrição de duzentos verbos ingleses e portugueses.

\begin{tabular}{|c|c|c|}
\hline & Arguer & Irregularity \\
\hline impugnar $_{2}$ & autor, recorrente, réu & $\begin{array}{l}\text { acórdão, assinatura, condenação, dano, } \\
\text { decisão, decisão de facto, } \\
\text { despedimento, documento, } \\
\text { entendimento, facto, factualidade, } \\
\text { fundamento, letra, matéria de facto, } \\
\text { parte, prova, valor, versão }\end{array}$ \\
\hline invocar $_{1}$ & autor, recorrente, réu & $\begin{array}{l}\text { abuso, alteração, caso, circunstância, } \\
\text { excepção, facto, factualidade, } \\
\text { fundamento, nulidade, resolução, } \\
\text { violação }\end{array}$ \\
\hline arguir $_{1}$ & autor, recorrente, requerido, réu & $\begin{array}{l}\text { culpa, excepção, ilegitimidade, } \\
\text { incompetência, ineptidão, nulidade }\end{array}$ \\
\hline
\end{tabular}

Tabela 1. Realizações linguísticas dos actantes de impugnar2, invocarı e arguirı.

Concluído este processo, programámos pesquisas automáticas na base de dados que identificassem termos com características comuns (a mesma etiqueta de frame, o mesmo número de actantes, as mesmas realizações linguísticas, etc.). Assim, verificámos que os 
termos portugueses impugnar 2 e invocar 1 pertenciam à mesma frame que arguir $_{1}$. Todavia, ao compararmos as realizações linguísticas dos seus actantes, percebemos que o tipo de irregularidades que um réu ou um recorrente impugna é mais variado do que aquelas que ele invoca ou argui (Tabela 1). Apesar desta diferença, os três verbos evocam um cenário em que alguém apresenta uma declaração, uma razão ou facto a favor ou contra a matéria em discussão, questionando assim a validade de uma declaração ou de um facto. A frame [Contesting] inclui, portanto, três termos que não são sinónimos perfeitos.

Da mesma forma que os verbos na mesma língua foram organizados por frames se as suas descrições continham as mesmas etiquetas, dois ou mais verbos em português e em inglês foram considerados candidatos a equivalentes se nas suas descrições encontrássemos as mesmas etiquetas. Isto reflecte a ideia segundo a qual as frames podem funcionar como tertia comparationis (BOAS, 2005; BAKER, 2009). Por exemplo, os verbos allege , impugn $_{1}$, rebut $_{1}$, arguir, impugnar $_{1}$ e invocar ${ }_{1}$ foram automaticamente identificados como sendo candidatos a equivalentes porque tinham a mesma etiqueta de frame (Tabela 2).

\begin{tabular}{|c|c|c|c|c|c|c|c|}
\hline \multicolumn{8}{|c|}{ Contesting } \\
\hline & & impugn.1.en & rebut.1.en & arguir.1.pt & impugnar.2.pt & invocar. $1 . \mathrm{pt}$ & allege.1.en \\
\hline \multirow[t]{3}{*}{$\underline{\text { Core Elements }}$} & Arguer & 5 & 8 & 15 & 18 & 16 & 19 \\
\hline & Evidence & & 13 & & & & \\
\hline & Irregularity & 20 & 20 & 19 & 23 & 19 & 22 \\
\hline \multirow[t]{8}{*}{$\underline{\text { Non Core Elements }}$} & Basis & 6 & 1 & 2 & 2 & 1 & \\
\hline & Case & & & & & 2 & \\
\hline & Condition & & 1 & & & & \\
\hline & Evidence & & & & & & \\
\hline & Manner & 2 & 1 & & & & 1 \\
\hline & Mode & 2 & 1 & & 1 & & \\
\hline & Place & & & & 1 & & 1 \\
\hline & Purpose & & & & & 1 & \\
\hline
\end{tabular}

Tabela 2. Candidatos a equivalentes extraídos automaticamente. 
Trata-se, portanto, de seis termos e de nove pares de candidatos a equivalentes: arguir 1 e allege $_{1} ; \operatorname{arguir}_{1}$ e impugn ; $_{\text {arguir }}$ e rebut; impugnar 2 e allege 1 ; impugnar 2 e impugnl;

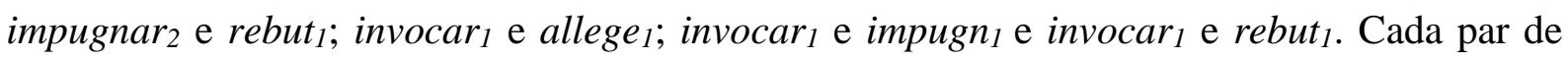
equivalentes foi então estudado cuidadosamente de modo a confirmar se são realmente equivalentes. Se forem equivalentes, é necessário examinar se são equivalentes totais ou parciais e justificar o grau de equivalência. Para tal, comparou-se as descrições dos verbos, nomeadamente:

- A forma como os verbos evocam a frame. Aqui, examina-se se os verbos evocam a frame da mesma maneira. Pode haver alguns casos em que os verbos numa língua tenham o sentido contrário dos verbos noutra língua, pois alguns termos podem evocar a frame de uma forma negativa (por exemplo, os antónimos). Noutros casos, os verbos que foram agrupados na mesma frame podem não ser sinónimos perfeitos dentro de cada língua.

- As estruturas actanciais dos verbos. Nesta etapa comparamos o número de actantes dos pares de candidatos a equivalentes. Por exemplo, a partir da Tabela 2, podemos observar que todos os verbos têm dois actantes excepto o termo rebut 1 que tem três. Rebut 1 é necessariamente um equivalente parcial dos verbos portugueses arguir 1 , impugnar 1 e invocar 1 porque o actante Evidence nunca é exprimido nos contextos dos verbos portugueses (Tabela 3).

- As realizações linguísticas dos core FEs. As realizações linguísticas das actantes são analisadas, de modo a verificar se a natureza dos actantes dos verbos é totalmente idêntica. Por exemplo, as realizações linguísticas de Arguer dos verbos ingleses e dos verbos portugueses referem-se ao mesmo tipo de entidades (Tabela 3). No entanto, as realizações linguísticas de Irregularity nos contextos dos verbos arguir $_{1}$ e invocar $_{1}$ denotam entidades que têm uma conotação mais negativa do que as indicadas pelo actante de impugn $n_{1}$ enquanto que as realizações linguísticas de Irregularity nos contextos de impugnar 2 são bastante comparáveis às do verbo

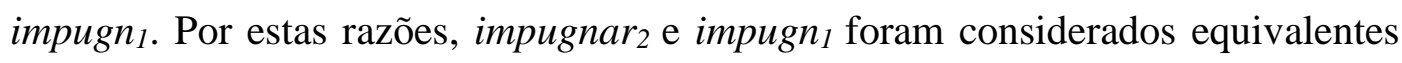
totais, e os pares arguir -impugn $_{1}$ e invocar-impugn $n_{1}$ foram considerados equivalentes parciais. 


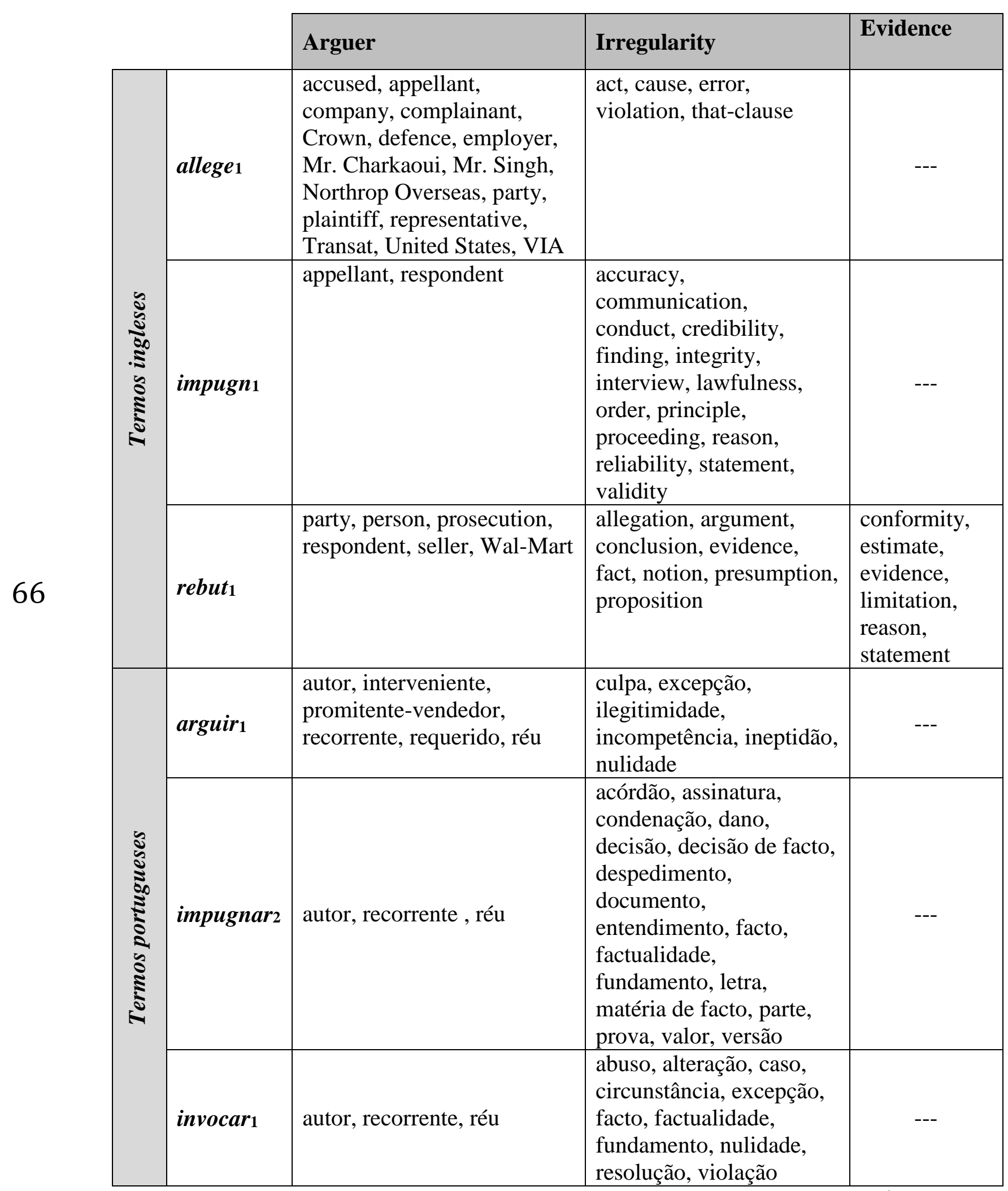

Tabela 3. Estruturas actanciais dos candidatos a equivalentes e suas realizações linguísticas. 
Sempre que um par de verbos tinha mais do que um equivalente (parcial e/ou total), estes foram listados na base de dados juntamente com uma etiqueta indicando o seu estatuto de equivalência. Na secção seguinte, comprovaremos os resultados da aplicação desta metodologia por meio da tradução de contextos tirados do corpus.

\section{Da traduzibilidade da terminologia jurídica}

Na secção precedente, descreveu-se a metodologia que nos permitiu identificar de uma forma semi-automática os equivalentes totais e parciais de termos jurídicos que ocorrem as decisões da mais alta instância dos tribunais do Canadá e de Portugal. Conforme relatado em PIMENTEL (2012), a metodologia permitiu, numa fase inicial, o agrupamento de 200 verbos em 76 frames e a identificação de 165 pares de equivalentes. Entre estes, 117 pares de equivalentes $(71 \%)$ foram considerados equivalentes totais e 48 pares de equivalentes (29\%) foram considerados equivalentes parciais. Os equivalentes totais evocam a mesma frame da mesma maneira (positiva ou negativa), e têm o mesmo número e tipo de actantes. Os equivalentes parciais podem não ter o mesmo número de actantes, ou os actantes podem ser exprimidos por termos com semânticas diferentes. Por exemplo, os actantes de um termo numa língua podem ter uma conotação mais ou menos negativa do que os actantes do seu equivalente.

Os exemplos [1] a [3] ilustram a tradução dos verbos ingleses utilizando os equivalentes portugueses indicados no JuriDico e os exemplos [4] a [6] ilustram a tradução que propomos dos verbos portugueses utilizando os equivalentes ingleses. Pode observar-se que as traduções marcadas com o símbolo (!) correspondem a traduções menos apropriadas porque o equivalente utilizado é um equivalente parcial:

[1] allege $_{1}$ [Contesting]: Arguer Irregularity

At trial, the accused ${ }_{\text {[Arguer] }}$ alleged violations of his rights ${ }_{[\text {Irregularity] }}$ under ss. 8, 9 and 10(b) of the Canadian Charter of Rights and Freedoms. (Source: SCC-2009-32)

[1a] arguir $_{1}$ [Contesting]: Arguer Irregularity

Em tribunal, o acusado [Arguer] arguiu a violação dos seus direitos [Irregularity] estabelecidos nas alíneas 8, 9 e 10(b) da lei canadiana sobre direitos e liberdades.

[1b] impugnar 2 [Contesting]: Arguer Irregularity

(!) Em tribunal, o acusado [Arguer] impugnou a violação dos seus direitos [Irregularity] estabelecidos nas alíneas 8, 9 e 10(b) da lei canadiana sobre direitos e liberdades.

[1c] invocar 1 [Contesting]: Arguer Irregularity 
Em tribunal, o acusado [Arguer] invocou a violação dos seus direitos [Irregularity] estabelecidos nas alíneas 8, 9 e 10(b) da lei canadiana sobre direitos e liberdades.

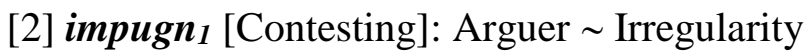

For example, the respondent [Arguer] seeks to impugn Mr. Kong's credibility [Irregularity] by pointing to his inability to accurately describe his injuries in a manner consistent with the medical records. (Source: SCC-2009-22)

[2a] arguir 1 [Contesting]: Arguer Irregularity

(!) Por exemplo, o requerido [Arguer] arguiu a credibilidade de Mr. Kong [Irregularity] ao apontar para a sua incapacidade em descrever os seus ferimentos de uma forma precisa e consistente com os relatórios médicos.

[2b] impugnar2 [Contesting]: Arguer Irregularity

Por exemplo, o requerido [Arguer] impugnou a credibilidade de Mr. Kong [Irregularity] ao apontar para a sua incapacidade em descrever os seus ferimentos de uma forma precisa e consistente com os relatórios médicos.

[2c] invocar ${ }_{1}$ [Contesting]: Arguer Irregularity

(!) Por exemplo, o requerido [Arguer] invocou a credibilidade de Mr. Kong [Irregularity] ao apontar 68 com os relatórios médicos.

[3] rebut ${ }_{1}$ [Contesting]: Arguer Irregularity with Evidence

The prosecution [Arguer] could rebut the presumption [Irregularity] with evidence that the child had sufficient intelligence and experience to "know the nature and consequences of the conduct and to appreciate that it was wrong" [Evidence] (p. 45). (Source: SCC-2008-25).

[3a] arguir $_{1}$ [Contesting]: Arguer Irregularity

(!) O Ministério Público [Arguer] pode arguir a presunção [Irregularity] com a prova de que a criança era suficientemente inteligente e tinha experiência para reconhecer a natureza e as consequências da conduta e saber que era errado [Evidence].

[3b] impugnar2 [Contesting]: Arguer Irregularity

(!) O Ministério Público [Arguer] pode impugnar a presunção [Irregularity] com a prova de que a criança era suficientemente inteligente e tinha experiência para reconhecer a natureza e as consequências da conduta e saber que era errado [Evidence].

[3c] invocar ${ }_{1}$ [Contesting]: Arguer Irregularity

(!) O Ministério Público [Arguer] pode invocar a presunção [Irregularity] com a prova de que a criança era suficientemente inteligente e tinha experiência para reconhecer a natureza e as consequências da conduta e saber que era errado [Evidence].

[4] arguir 1Contesting]: Arguer Irregularity 
As Intervenientes $J J$ e $K K_{\text {[Arguer] }}$ recorreram contra o acórdão da Relação do Porto arguindo a existência de culpa concorrente [Irregularity]. (Source: STJ-dez2009-18)

[4a] allege ${ }_{1}$ [Contesting]: Arguer Irregularity

JJ and KK [Arguer] lodged an appeal against the judgment made by Oporto's Court and alleged that there was a concurrent guilt [Irregularity].

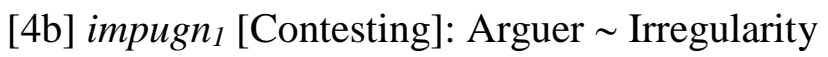

(!) JJ and KK [Arguer] lodged an appeal against the judgment made by Oporto's Court and impugned a concurrent guilt [Irregularity].

[4c] rebut ${ }_{1}$ [Contesting]: Arguer Irregularity with Evidence

(!) JJ and KK [Arguer] lodged an appeal against the judgment made by Oporto's Court and rebutted a concurrent guilt [Irregularity].

[5] impugnar 2 [Contesting]: Arguer Irregularity

Finalmente, a recorrente [Arguer] impugna condenação no pagamento de 4.000 por danos não

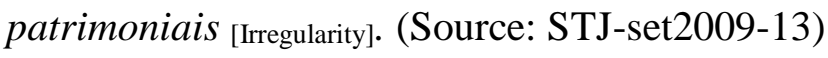

[5a] allege $_{1}$ [Contesting]: Arguer $\sim$ Irregularity

(!) Finally, the appellant [Arguer] alleged that the order [Irregularity] to pay 4.000 for personal injury is unfair.

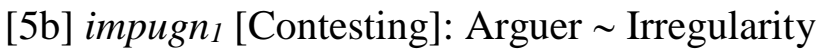

Finally, the appellant ${ }_{\text {[Arguer] }}$ impugned the order ${ }_{\text {[Irregularity] }}$ to pay 4.000 for personal injury.

[5c] rebut ${ }_{1}$ [Contesting]: Arguer Irregularity with Evidence

(!) Finally, the appellant [Arguer] rebutted the order [Irregularity] to pay 4.000 for personal injury.

[6] invocar 1 [Contesting]: Arguer Irregularity

A recorrente ${ }_{[\mathrm{Arguer}}$ invoca abuso de direito por parte da autora. (Source: STJ-nov2009-43)

[6a] allege $_{1}$ [Contesting]: Arguer Irregularity

The appellant ${ }_{\text {[Arguer] }}$ alleged that the plaintiff abused a right [Irregularity].

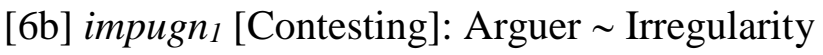

(!) The appellant ${ }_{\text {[Arguer] impugned the abuse of right }}^{\text {[Irregularity] }}$ by the plaintiff.

[6c] rebut ${ }_{1}$ [Contesting]: Arguer Irregularity with Evidence

(!) The appellant ${ }_{[\text {Arguer] }}$ rebutted the abuse of right ${ }_{[\text {Irregularity] }}$ by the plaintiff.

Por exemplo, impugnar 2 é um equivalente parcial de allege $_{1}$ porque o primeiro tende a combinar-se com termos que têm uma conotação menos negativa do que o segundo. No caso dos equivalentes de rebut, é estranho dizer arguir a presunção com a prova de ou invocar a presunção com a prova de, porque, em discurso, estes últimos não costumam associar-se a este tipo de complementos. Todavia, na grande maioria dos casos existe pelo menos um equivalente total para cada verbo especializado. 


\section{Conclusões}

Nesta contribuição, abordou-se a tradução da terminologia jurídica, que é por vezes encarada como sendo impossível, sobretudo quando se ela ocorre em textos produzidos por tradições jurídicas diferentes, comunidades linguísticas diferentes, e países diferentes. O objectivo deste trabalho era mostrar que a impossibilidade da terminologia jurídica tem de ser relativizada pois, com maior ou menor dificuldade, tradutores e terminólogos são sempre capazes de transmitir conceitos. Mais precisamente, apresentámos o esboço de um dicionário bilingue jurídico para tradutores que foi compilado a partir de um corpus de textos que incorporam todas estas diferenças: o direito civil e a common law, o português e o inglês, Portugal e o Canadá.

Este dicionário teve como ponto de partida os verbos especializados pois estes, enquanto unidades predicativas cujos actantes ou argumentos são frequentemente expressos em discurso, facilitam a tarefa de identificação dos equivalentes. Utilizámos a teoria da semântica das frames e a metodologia da FrameNet (RUPPENHOFER et al. 2010) para analisar o conteúdo semântico dos verbos, bem como seu contexto colocacional porque as frames agrupam termos com um comportamento sintáctico-semântico comparável. Estas também funcionaram como uma espécie de tertium comparationis que nos permitiu estabelecer as correspondências entre termos em línguas diferentes. Apesar de alguns pares de equivalentes não funcionarem tão bem quanto outros numa tradução, a maioria deles funcionam, o que nos leva a concluir que, pelo menos, a tradução dos verbos especializados que ocorrem nas decisões dos supremos tribunais de justiça de Portugal e do Canadá é possível.

\section{Agradecimentos}

O trabalho aqui descrito foi financiado pela Fundação para a Ciência e Tecnologia, Ministério da Educação e do Ensino Superior de Portugal (FCT-MCTES) bem como pelo Social Sciences and Humanities Research Council of Canada (SSHRC). 


\section{REFERÊNCIAS BIBLIOGRÁFICAS}

ANTUNES, Maria João. As garantias do arguido no processo penal português. Janus, 2004. Disponível em http://www.janusonline.pt/2004/2004_3_4_3.html. Acesso em 8 agosto 2013.

BAKER, Collin. La sémantique des cadres et le projet FrameNet : une approche différente de la notion de «valence ». Langages, n. 4, p. 32-49, 2009.

BOAS, Hans. Semantic Frames as Interlingual Representations for Multilingual Lexical Databases. International Journal of Lexicography, ano 18, n. 4, p. 39-65, 2005.

CAO, Deborah. Translating Law. Clevedon: Multilingual Matters, 2007.

DAVID, René. Les grands systèmes de droit contemporains. Paris: Dalloz, 1974.

DROUIN, Patrick. Term Extraction Using Non-technical Corpora as a Point of Leverage. Terminology, ano 9, n. 1, p. 99-115, 2003.

FILLMORE, Charles. Frame semantics and the nature of language. Annals of the New York Academy of Sciences: Conference on the Origin and Development of Language and Speech, ano 280 (1976), p. 20-32, 1976.

FILLMORE, Charles. Scenes-and-Frames Semantics, Linguistic Structures Processing. In: ZAMPOLLI, Antonio (Ed.) Fundamental Studies in Computer Science, n. 59, p. 55-88, North Holland Publishing, 1977.

FILLMORE, Charles. Frame Semantics. In: Linguistics in the Morning Calm. Seoul: Hanshin Publishing Co., p. 111-137, 1982.

FILLMORE, Charles. Frames and the Semantics of Understanding. Quaderni di Semantica, ano 6, n. 2, p. 222-254, 1985.

FILLMORE, Charles; ATKINS, Sue Towards a Frame-based Lexicon: The semantics of RISK and its Neighbors. In: LEHRER, A.; KITTAY, E. (Eds.) Frames, Fields, and Contrast: New Essays in Semantics and Lexical Organization. Hillsdale: Lawrence Erlbaum Associates, p. 75-102, 1992.

(de) GROOT, Gerard-René; van LAER, Conrad. The Quality of Legal Dictionaries: an Assessment. Maastricht Faculty of Law Working Paper No. 2008/6, 2008. Disponível em http://papers.ssrn.com/sol3/papers.cfm?abstractid=1287603; http://arno.unimaas.nl/show.cgi?f id=13383). Acesso em 8 agosto 2013.

HARVEY, Malcolm. Traduire l'intraduisible. Stratégies d'équivalence. In: LAVAULTOLLÉON, Elizabeth (Ed.) Le facteur culturel dans la traduction des textes pragmatiques, Les Cahiers de l'ILCEA 3 (2001-2002). Université Stendhal-Grenoble, p. 39-50, 2002.

L'HOMME, Marie-Claude. La terminologie : principes et techniques. Montréal: Presses de l'Université de Montréal, 2004.

L'HOMME, Marie-Claude. Le DiCoInfo. Méthodologie pour une nouvelle génération de dictionnaires spécialisés. Traduire, n. 217, p. 78-103, 2008. 
MOUNIN, Georges. Les problèmes théoriques de la traduction. Paris: Gallimard, 1965.

(de) PEDRO, Raquel. The Translatability of Texts: A Historical Overview. Meta, ano 44, n. 4, p. 546-559, 1999.

PIMENTEL, Janine. Criteria for the Validation of Specialized Verb Equivalents: Applications in Bilingual Terminography. Montreal, 2012. Dissertação (Doutoramento em Tradução) - Universidade de Montreal, Montreal, 2012.

POIRIER, Donald. Les trois fonctions de la traduction dans la création et le développement de la common law e français. In: GÉMAR, Jean-Claude; KASIRER, Nicholas (Eds.) La jurilinguistique. Entre langues et droits - Jurilinguistics. Between law and langage. Montréal / Bruxelles: Thémis / Bruylant, p. 551-564, 2005.

PRATA, Ana. Dicionário Jurídico (Direito Civil, Direito Processual Civil, Organizaçao Judiciária). Coimbra: Almedina, 2005.

ROGERS, Margaret. Terminological Equivalence in Technical Translation: A problematic Concept? St. Jerome and Technical Translation. SYNAPS. Fagspråk, Kommunikasjon, Kulturkunnskap, n. 20, p. 13-25, 2008.

RUPPENHOFER, Jan; ELLSWORTH, Michael; PETRUCK, Miriam; JOHNSON, Charles; SCHEFFCZYK, Jan. FrameNet II: Extended Theory and Practice. ICSI Technical Report. 72 2000. Disponível em http://framenet2.icsi.berkeley.edu/docs/r1.5/book.pdf. Acesso em 8 agosto 2013.

SACCO, Rodolfo. La comparaison juridique au service de la connaissance du droit. Paris: Economica, 1991.

SANTOS, Manuel; LEAL-HENRIQUES, Manuel; SANTOS, Joao. Noções de Processo Penal. Lisboa: Rei dos Livros, 2010.

WÜSTER, Eugen. The Machine Tool. An Interlingual Dictionary of Basic Concepts. London: Technical Press, 1969.

\footnotetext{
i Currículo Lattes. Janine Pimentel. Disponível em: http://janinepimentel.com/.

ii Observatoire de linguistique Sens-Texte

iii Centro de Linguística da Universidade Nova de Lisboa
} 